\title{
Avaliação de um software de autoria coletiva: experiências com pessoas com necessidades especiais
}

\author{
Daniela Bagatini - UNISC - bagatini@unisc.br \\ Fernando Teles - UFRGS - nandotelles@ gmail.com \\ Nelson Jr. - ESADE - juniornelson@gmail.com \\ Débora Conforto - UFRGS - deboraconforto@gmail.com \\ Lucila Santarosa - UFRGS - lucila.santarosa@ufrgs.br \\ Valderi Leithardt - UFRGS - profvalderi@ gmail.com \\ Cleci Maraschin - UFRGS - cleci.maraschin@gmail.com
}

Resumo. Este artigo apresenta os relatos de experiências da interação de usuários com necessidades especiais com a ferramenta síncrona de autoria coletiva - Twiddla, com o objetivo de analisar requisitos de usabilidade e de acessibilidade. A investigação foi realizada por meio de uma metodologia exploratória, envolvendo uma etapa de verificação e de validação das normativas de acessibilidade e de heurísticas de usabilidade, tendo com sujeitos de análise usuários com deficiência auditiva e visual.

Palavras-chave: acessibilidade, usabilidade, ferramenta de autoria coletiva, PNE.

\section{Evaluation of a synchronous authoring software: experiences with people with disability}

Abstract. This paper presents reports on experiments carried out with disabled people in interaction with the synchronous authoring tool - Twiddla, aiming at the analysis of acessibility and usability criteria. The investigation was done through an exploratory methodology, which involved a stage of examination and validation of acessibility requirements as well as usability heuristics, having as research participants, visually and hearing impaired users.

Keywords: accessibility, usability, synchronous authoring tool, disabled people.

\section{Introdução}

As TIC têm permitido expandir as possibilidades de educação e expressão da cidadania ao instituírem meios inéditos e inovadores de comunicação e colaboração. Além disso, participam como catalisadores da organização social e tendem a ocupar diferentes espaços de interação. Seu uso recorrente sugere sua integração onipresente às mais diversas práticas da vida humana.

Contudo, avanços tecnológicos ainda não atendem a toda a diversidade dos coletivos humanos que são ou serão, algum dia, seus usuários, conforme apresentam os estudos da W3C (World Wide Web Consortium), que pesquisam a acessibilidade com o objetivo de desenvolver padrões de tecnologias para a Web (Chishlm et al, 1999). Afinal, como construir e disponibilizar recursos informacionais que alcancem pessoas com necessidades especiais (PNE)? Este questionamento orientou nosso interesse em investigar as possibilidades de acesso e de interação de uma ferramenta de autoria colaborativa diante das necessidades de usuários com deficiências auditivas e visuais.

Com base nisso, o presente texto discorre sobre possibilidades de uso das tecnologias e relata experiências de campo com o software Twiddla. A partir de exercícios práticos de desenhos conduzidos com usuários, procuramos analisar elementos que concorrem para a qualidade do referido software em termos de usabilidade e acessibilidade. 


\section{Por uma computação mais inclusiva e participativa}

$\mathrm{Na}$ esteira das transformações coletivas impulsionadas pelas Tecnologias da Informação e da Comunicação (TIC), a proliferação de recursos computacionais contribui para a constituição de novas formas de participação social. A popularização da Internet e a apropriação informal de seus recursos têm produzido modos específicos de sociabilidade, cognição e aprendizagem. A educação, por exemplo, enfrenta o abismo que separa uma geração de aprendizes habituada à tecnologia de um modelo de escola ainda conservador (Mattar, 2010). Tal abismo parece ainda mais amplo se considerarmos que a difusão das TIC privilegia o acesso de um público específico. Trata-se de reconhecer que a diversidade humana carece de inclusão nas pautas que procuram democratizar o direito à educação e à informação. Como oferecer oportunidades iguais para o uso da tecnologia em meio às diferenças que ainda excluem as pessoas com necessidades especiais?

Paradoxalmente, as possibilidades de participação e uso colaborativo da Internet sofreram uma surpreendente expansão nos últimos anos. Tal fenômeno ficou conhecido como Web 2.0, em alusão à noção de que a rede mundial de computadores estaria em uma segunda fase de sua existência (Primo, 2006; O'Reilly, 2005; Jenkins, 2006). A Web 2.0 oferece um variado leque de opções gratuitas de interação e extrai da colaboração e da participação dos usuários o principal recurso para sua manutenção e sobrevivência (Coutinho e Júnior, 2007; O'Reilly, 2005). É neste contexto que os Blogs, os Wikis e as redes sociais surgiram como plataformas que permitem que o usuário atue, ao mesmo tempo, como consumidor e produtor de informação. A qualidade dos serviços web passou a ser medida pelo número de usuários que conseguem agregar e que, por sua vez, difundem estes mesmos serviços ao longo da rede.

Como mais uma dimensão de possibilidade de pensar e agir na vida cotidiana é possível considerarmos que o advento da Web 2.0 trouxe consigo a marca da participação em coletivos, tendo em vista que o internauta migrou de uma condição de espectador para uma posição de autor, capaz de expressar interesses, opiniões e mobilizar outros no estabelecimento de grupos de discussão e comunidades online. Simultaneamente, segundo Jenkins (2006), o cenário atual exige habilidades sociais específicas para a realização de uma participação efetiva na cultura digital, como: capacidade de explorar ambientes para a resolução de problemas; mixar conteúdos midiáticos; saber trabalhar em conjunto para a busca de conhecimento; utilizar diferentes modalidades e tipos de mídia para ao acompanhar o fluxo de produção de uma informação; e, entre outros, ter a capacidade de trafegar em meio às mais diversas comunidades respeitando e reconhecendo normas e posicionamentos distintos. Os recursos implicam uma nova modalidade de alfabetização para se tornarem potentes ferramentas de participação e de autoria.

O momento atual permite que além da troca de informações possamos vivenciar o trabalho colaborativo e a interatividade. Nesse sentido, Primo (2007) comenta que é necessário não apenas oferecer espaços para fácil publicação ou debates, mas sim recursos para gestão coletiva do trabalho comum. Este engendramento, chamado por Primo de arquitetura de participação, potencializa a coparticipação e coprodução para a construção colaborativa de conhecimento apoiada pela informática. É dentro deste cenário de participação que as pessoas atuam colaborativamente, geram e compartilham informações, agregam conhecimentos e vivenciam experiências. Assim, os sujeitos e as comunidades interagem e crescem mutuamente.

No entanto, as interfaces da Web 2.0 não parecem estar preparadas para atender à diversidade humana, principalmente diante das especificidades das deficiências 
físicas, auditivas, visuais, entre outras. Segundo o estudo de Oliveira (2009), a maioria dos produtos da nova Internet é constituída por tecnologias muito novas, baseadas em um uso expressivo de gráficos e não adequadas aos padrões de acessibilidade vigentes. Muitos dos componentes técnicos que definem a estrutura dos websites e que caracterizam o fenômeno da Web 2.0 possuem complexidades particulares sem compromissos com um protocolo comum. A presença de linguagens sofisticadas de programação em meio à organização de uma página, por exemplo, dificulta que a mesma possa ser lida com o apoio de tecnologias assistivas, como é o caso dos leitores de tela utilizados por deficientes visuais.

Para tornar a Web 2.0 acessível a todas as pessoas (onde todos tenham acesso ao seu conteúdo), muitas vezes devemos atender a princípios bastantes simples como: acessibilidade e usabilidade. Por acessibilidade, entendemos o conjunto de esforços que visam proporcionar um maior acesso das pessoas a meios e recursos sociais, culturais, educacionais, entre outros, com o objetivo de reduzir o efeito de uma limitação própria ou do ambiente, garantido a mobilidade, neste caso, a recursos computacionais (Conforto e Santarosa, 2002). Ao avaliarmos a acessibilidade de um software, devemos observar se sua interface é:

- Perceptível: o conteúdo deve ser apresentado de forma clara e em diferentes formatos, sem perder informação ou estrutura.

- Operável: todas as funcionalidades devem estar disponíveis no teclado e devem prover tempo suficiente para os usuários lerem, usarem o conteúdo e obter ajuda para navegar e localizar conteúdos.

- Compreensível: o conteúdo deve ser legível e funcionar de modo previsível, evitando que o usuário comenta erros ou ajudando-o a corrigi-los.

- Robusto: compatibilidade entre os atuais e futuros agentes do usuário, incluindo as tecnologias assistivas.

Quanto à usabilidade, o termo é sinônimo de facilidade de uso. Assim, Jakob Nielsen (1993) apresenta heurísticas de usabilidade, entre as quais destacamos:

- Consistência: falar a mesma língua o tempo todo (padrão), ou seja, tratar de coisas similares, da mesma maneira facilitando a identificação do usuário e evitar que tenha que reaprender a cada nova seção ou aparelho diferente.

- Compatibilidade com o mundo real: consiste em não usar palavras de sistema, que não fazem sentido para o usuário. Toda a comunicação do sistema precisa ser contextualizada ao usuário.

- Feedback: consiste em informar ao usuário o que está acontecendo, ou seja, todas as ações precisam de feedback instantâneo para orientá-lo.

No ciberespaço, muitos de nós ainda estamos isolados da construção efetiva de conhecimentos, limitados pelo uso de recursos mediadores ou por nossa incapacidade de torná-los acessíveis e garantir a participação de todos os sujeitos. É a partir daí que consideramos a multiplicidade de meios de interação que serão utilizados e o amadurecimento necessário dos padrões de acessibilidade vigentes. Afirmamos que é imperativo um olhar mais abrangente, bem como uma preocupação maior por parte dos projetistas e designers de aplicações, sejam elas pervasivas ou não, a fim de proporcionar melhorias progressivas e significativas para as pessoas com necessidades especiais (PNE). Por isso, todo aparato computacional, conectado ou não a outros dispositivos e redes, precisa acolher a diversidade humana de maneira transparente, seja nas atividades sociais ou profissionais (Demoly, 2008).

\section{Metodologia}


No intuito de verificar o potencial de uma ferramenta de autoria coletiva em atender às demandas de pessoas com necessidades especiais, procuramos observar e ouvir usuários durante sessões sistematizadas de interação. Fomos movidos pelo interesse de compreender como PNEs reagiriam a um primeiro contato com uma ferramenta. Para tanto, nossa atenção esteve voltada ao modo como sua interface está mais ou menos ajustada às capacidades de indivíduos com deficiência auditiva e visual.

A fim de deflagrar as condições de avaliação da adequação de um software às necessidades dos referidos indivíduos, elegemos como corpus de análise o software Twiddla, http://www.twiddla.com. Este software consiste em uma plataforma para a construção de conhecimento em grupos de trabalho com objetivos comuns. Sob tais considerações, procuramos verificar a acessibilidade e a usabilidade do software a partir da análise de sua interação com o usuário.

O Twiddla apresenta um conjunto de recursos como: quadro-branco para produção livre de texto e desenho, edição de documentos, construção de sites, entre outros. Neste estudo, acompanhamos a interação dos sujeitos com o recurso quadrobranco. No quadro-branco do Twiddla é possível realizar desenho livre, inserir texto, formas, imagens, documentos, widgets (componentes de uma interface gráfica) e fórmulas matemáticas. Ele também apresenta recursos de interação como chat de texto e voz.

Para a condução deste trabalho, contamos com a participação de quatro pessoas: duas com necessidades auditivas e duas com necessidades visuais. Cada sujeito participou individualmente da condução das atividades deste estudo. Como ponto de partida, decidimos oferecer exercícios práticos de desenho, chamados de desafios, que pudessem propiciar o uso livre do recurso quadro-branco para que a qualidade da interação entre software e usuário se fizesse observável.

Para tanto, apresentamos resumidamente a função do quadro-branco e informamos ao usuário os objetivos do estudo. Em seguida, mostramos a ele os elementos da interface, discorrendo brevemente sobre suas funções. Após esta exposição, apresentamos uma visão geral do quadro-branco, falando sobre os principais elementos da interface. Procuramos destacar onde se localizavam as barras de ferramentas superior e inferior e a janela de chat. Não pretendíamos aprofundar nos detalhes específicos de cada objeto da interface, mesmo assim, fornecemos um panorama das diversas possibilidades de uso dos recursos do quadro-branco. Como protocolo de pesquisa propusemos dois desafios ao usuário, um de caráter individual e outro, com um enfoque colaborativo.

O Desafio 1 consistia em descrever uma notícia ou algo que tenha sido relevante para ele nos últimos dias. Durante os primeiros 15 minutos da atividade, aproximadamente, o usuário explorou a ferramenta para criar um desenho que descrevesse um episódio divulgado pela imprensa ou algo que fosse relevante para ele, que lhe atraiu a atenção. Após a realização do primeiro desafio, o usuário recebeu um convite via chat, no quadro-branco, para a realização do Desafio 2, participar da criação de uma peça de forma colaborativa, com um outro usuário remoto. Nesta atividade, o usuário atende a um chamado surpresa feito pelo próprio pesquisador, que também esteve conectado a sessão do Twiddla durante a realização dos testes. Nesta ocasião, propusemos que o sujeito procurasse auxiliar na criação de um desenho livre iniciado pelo pesquisador.

As sessões foram registradas com uma câmera de vídeo acoplada ao computador do usuário e outra câmera direcionada a ele e à tela do computador, por outro ângulo. Enquanto o pesquisador interagia com o usuário, através do quadro-branco, a segunda câmera registrava a interação. Além disso, salvamos as imagens produzidas pelos 
sujeitos durante as atividades para posterior comparação. No caso dos sujeitos com deficiência visual, durante a interação, eles também faziam comentários sobre quaisquer dificuldades que estivessem enfrentando. Na etapa seguinte, convidamos o sujeito a responder um breve questionário, pré-elaborado, contendo as perguntas que consideramos mais pertinentes para a avaliação da usabilidade e da acessibilidade do software. As perguntas do questionário (Quadro 1) visavam inquirir acerca da acessibilidade e da usabilidade do Twiddla, conforme o julgamento do sujeito. Além de responder cada pergunta, ele também era encorajado a fazer qualquer comentário que acreditasse ser pertinente.

\section{Quadro 1. Questionário}

1. Você acha que o quadro-branco apresenta uma sobrecarga de informações, sejam essas textuais e/ou visuais?

2. A combinação de cores utilizada no quadro-branco é suficientemente contrastante para ser claramente visualizada?

3. É possível alterar o tamanho de textos e/ou imagens?

4. Os recursos que você utilizou funcionaram de forma esperada?

5. Você utilizou teclas de atalhos? Esses atalhos funcionaram como esperado?

6. Você conseguiu identificar facilmente botões que possuem a mesma funcionalidade?

7. Os desenhos dos ícones lhe ajudaram compreender melhor a função de cada um?

8. Os textos e palavras apresentados no quadro-branco são conhecidos por você?

9. Você acha que os elementos do quadro-branco estão bem posicionados na tela de forma que você pode identificá-los facilmente?

10. Se você tentou, conseguiu desfazer alguma ação?

11. Você achou fácil usar o quadro-branco?

12. Na sua opinião, é possível aprender de forma rápida como funciona o quadro-branco?

13. Em outra oportunidade, você acha que teria maior facilidade para usar o quadro-branco?

14. Se você pudesse, modificaria alguma coisa no quadro-branco? O quê?

No emprego do questionário e das demais estratégias metodológicas que expusemos acima, procuramos seguir as orientações metodológicas defendidas por Latour (2007) e Despret (2004; 2011), sobretudo, naquilo que concerne à relação entre pesquisador e pesquisado. Com base nestes autores, entendemos que a simetria é condição básica para a condução de qualquer estudo científico já que a fabricação de fatos é sempre resultado de um agenciamento entre humanos e não humanos. Ser simétrico em pesquisas com participantes humanos, entre outras coisas, implica em considerar a legitimidade da participação do sujeito como coautor das considerações que realizamos. O uso de um questionário e as demais decisões e disposições que definem nossa relação com nossos usuários são elementos que compõem nosso dispositivo experimental. Segundo Despret (1996), um dispositivo experimental é qualquer aparato que dispõe as atividades de uma pesquisa de modo criativo, realizando articulações inéditas no espaço de construção entre pesquisador e pesquisado.

Neste sentido, não é absoluto em sua capacidade de produzir dados, mas é sempre resultado de uma performance. Considerá-lo assim é também supor que seu papel em uma investigação é apenas mobilizar, acionar mecanismos de conduta. Esta noção, por si só, indica como nossos interesses de pesquisa incidem sobre a ação que desejamos observar. Nenhuma escolha metodológica é inocente, pois deixa escapar as particularidades de nossa própria articulação com o campo de estudo que torna válidos nossos questionamentos.

A pertinência de tais reflexões consiste em que saibamos compreender que, apesar de suas especificidades, o trabalho científico é fruto de um encontro social, como qualquer outro. Portanto, cabe ao pesquisador conduzir seus estudos com humanos de modo a resguardar um meio justo entre seus interesses e as disponibilidades de seus investigados. Só assim poderemos efetivar a simetria de modo a propiciar um espaço de construção e não de extorsão (Despret, 2011). Ser ético, neste sentido, é mais do que cumprir um rigor institucional, mas também assumir uma posição epistemológica que 
compreende o real como sinônimo de construção, que decorre do encontro entre investigador e investigado, sem concentração de poder.

Com base nisso, optamos por seguir esses preceitos a fim de interrogarmos os participantes de nosso estudo sem assujeitá-los a determinadas condições mas, ao contrário, tomar sua participação como manifestação genuína de co-autoria. Para tanto, apresentamos, adiante, uma sistematização das orientações teóricas que organizam nosso método.

A partir da leitura das obras de Vinciane Despret (2004) e Isabelle Stengers (1996), Latour (2007) enumera uma série de recomendações que comungam com sua proposta que sugere que, em ciência, ao falarmos de corpos ou sujeitos, não fazemos afirmações mas operamos articulações. Conforme já mencionamos, o conhecimento concebido como articulação é derivado do pressuposto de que a realidade para o cientista equivale à descrição de construções que este efetua com seu objeto de estudo. Decorre daí, a noção de que aprender é deixar-se afetar ou articular-se com entidades que estão à nossa volta, sejam humanas ou não humanas.

\section{Resultado das atividades}

Quatro pessoas participaram desta pesquisa: duas com necessidades auditivas e duas com necessidades visuais; todas são adultas e usuárias de computador. Os relatos a seguir descrevem as atividades realizadas com os sujeitos durante os experimentos com o quadro-branco do Twiddla. Tais relatos têm base nos registros das anotações, nos vídeos e nas respostas do questionário que coletamos durante as atividades, bem como nos comentários feitos pelos sujeitos. Desta forma, documentamos todo o processo mantendo foco principal na interação, no comportamento dos sujeitos e em seus relatos, para fazer emergir os pontos de fragilidade da ferramenta. A seguir, descrevemos detalhadamente cada uma das sessões de experimentação e indicamos o sistema operacional e o navegador utilizados para o acesso ao Twiddla. Preservarmos a identidade de cada participante na adoção de nomes fictícios para os mesmos. Os relatos abaixo consistem em descrições apuradas a partir dos métodos empregados neste estudo.

Sujeito 1 - Ana é professora, tem 28 anos, surda porém oralizada em português. Ela não encontrou dificuldades para se comunicar com os pesquisadores, dispensando intervenções de intérprete. Ela utilizou o sistema operacional Windows 7 e o navegador Chrome para interagir com o Twiddla.

Ana teve facilidade em interagir com a interface do quadro-branco, mesmo sem utilizar todos os recursos. Explorou mais as figuras geométricas, lápis, borracha e seleção (Figura 1). Ela ilustrou um smile e uma mão, simbolizando paz e amor. Observando a interação de Ana, ela não demonstrou reações que pudessem evidenciar dificuldades na interação com a ferramenta. Isto pode ser comprovado por suas respostas ao questionário. No final da atividade 1 o pesquisador sinaliza, com o desenho de uma seta indicativa, a janela de chat para uma conversa. Ana teve dificuldades para encontrar a janela de chat, por isso precisou da intervenção do pesquisador. $\mathrm{O}$ pesquisador a convidou para criar um desenho colaborativamente. Ana limpou o quadro-branco e os dois passaram a interagir pelo desenho, ambos como cocriadores da produção. Percebe-se que a interatividade emerge deste processo e o desenho passa a ganhar diferentes interpretações a cada novo elemento inserido. $\mathrm{O}$ envolvimento de Ana na segunda atividade indicava que ela havia se apropriado dos principais recursos do quadro-branco e que seu acesso à ferramenta tinha se tornado mais compreensível e operável. Por fim, Ana fez algumas considerações acerca do software. Ela alega não ter reconhecido alguns termos em inglês presentes na interface e sugere aprimoramento da 
identificação do acesso ao chat. Além disso, Ana considerou adequados os ícones e outras imagens que auxiliaram na identificação dos botões, mesmo tendo aumentado o tamanho da fonte para melhor visualização.

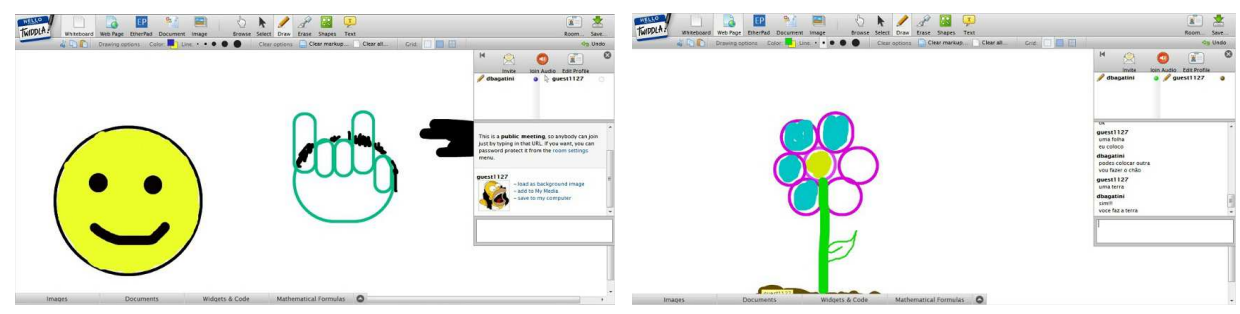

Figura 1. Desenho de Ana (a partir da tela do pesquisador)

Sujeito 2 - Pedro é estudante, 27 anos, supervisor de loja, tem perda auditiva sensorial hereditária, com níveis de surdez de moderado a severo no ouvido esquerdo e de leve a moderado no direito. Possui aparelhos auditivos, mas não os utilizou durante a interação com o Twiddla. Durante a atividade, ele utilizou o sistema operacional Ubuntu Linux11.04LTS e o navegador Firefox 8.0.

Como resposta ao primeiro desafio, Pedro produziu um esboço do que seria o episódio de desligamento de uma apresentadora de TV (Figura 2) de um conhecido telejornal. Ele tentou acessar a ferramenta de edição de texto para digitar a expressão "Fui!!!". Por mais de uma vez ele clicou sobre o ícone da referida ferramenta e procurou produzir uma caixa de texto no quadro-branco sem sucesso. De outro computador, o pesquisador entrou na mesma sessão no Twiddla e começou a desenhar no mesmo quadro-branco e, utilizando o chat, deixou mensagens indagando acerca do conteúdo do desenho. Porém, Pedro não conseguiu atender aos chamados. Ele alega que acreditava que a janela de chat fosse um mero bloco para a exibição de propagandas e não lhe pareceria fazer parte da interface funcional. Ele ainda acrescenta que a interface deveria possuir recursos visuais que destacassem esta caixa.

Pedro fez críticas à ferramenta eraser, utilizada para apagar conteúdo. Ele tentou ajustar o tamanho da borracha sem sucesso. Quanto ao uso de atalhos, utilizou o atalho CTRL+Z para desfazer ações enquanto produzia no quadro-branco. Além disso, ele também nos relata que a interface do Twiddla parece ser simples e de fácil operação, porém, nem todos os ícones são compreensíveis a qualquer usuário. Ele acredita que os termos no idioma inglês, que servem de rótulo a algumas ferramentas, poderiam restringir o acesso a usuários que conhecem essa língua.

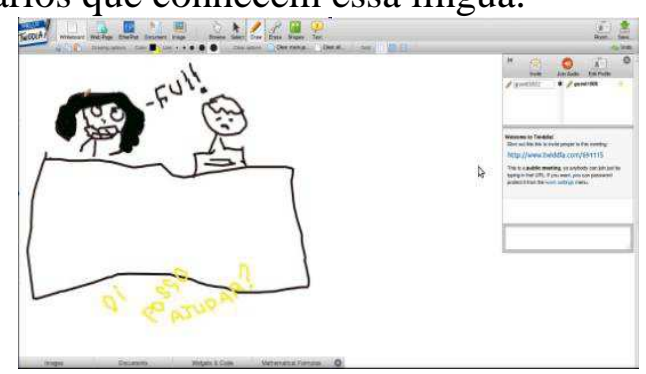

Figura 2. Desenho de Pedro (a partir da tela do pesquisador)

Sujeito 3 - Paulo é funcionário público estadual e possui 42 anos. Ele tem miopia severa, astigmatismo e disfunção congênita do nervo ótico, comprometendo assim, 15 graus de visão nos dois olhos e com apenas $30 \%$ de visão com correção. Durante a interação com o Twiddla, este participante utilizou o sistema operacional Windows 7 Pro e o navegador Mozilla Firefox 7.1. 
Paulo iniciou sua interação baseada em texto. Sua dificuldade fez com que ele se aproximasse muito da tela do computador e sua expressão facial se modificava na medida em que percebia maiores dificuldades. Ele explorou ferramentas de desenho livre e formas geométricas, porém não utilizou todos os recursos (Figura 3). Paulo questiona o porquê de a fonte do texto ser tão pequena. Paulo teve dificuldades para encontrar a janela de chat e precisou da intervenção do pesquisador para utilizá-la. Em diversas ocasiões, fechou, equivocadamente, a ferramenta quadro-branco. Durante o Desafio 2, percebemos pouca interatividade na construção colaborativa, tendo sido instigado pelo pesquisador. Ainda no segundo desafio, mantinha sua atenção à compreensão da ferramenta. Utilizou a área de chat com dificuldade em função dos tamanhos dos elementos e letras. Dentre as considerações feitas, ele comentou que o campo de texto é muito pequeno e os objetos fogem do seu campo de visão com o zoom. Ele afirma que confundiu cores e criticou o fato de que os termos em inglês, em alguns botões, dificultou sua compreensão. Ele também nos conta que os elementos do rodapé lhes parecem pouco visíveis. Reclamou sobre o tamanho do cursor e da área de chat que possui texto e elementos muito pequenos e que não podem ser redimensionados.

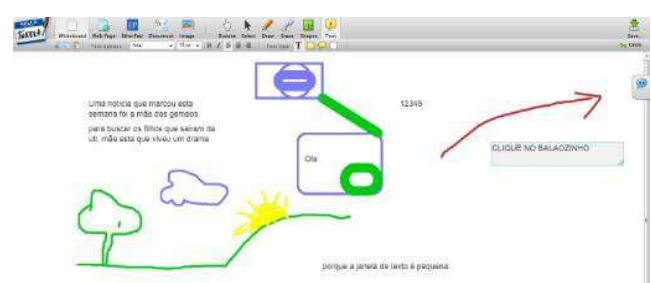

Figura 3. Desenho de Paulo (a partir da tela do pesquisador)

Sujeito 4 - João é Programador e tem 30 anos. Ele tem perda progressiva de nitidez na visão. Durante a interação, utilizou o sistema operacional Windows 7 Pro SP1 e o navegador Internet Explorar 9.

João iniciou sua interação a partir da ferramenta de texto. Por diversas vezes, desfez algumas ações (Figura 4). Inicialmente teve dificuldades pois, em seu dia-a-dia, utiliza acessórios de acessibilidade (lupa do sistema operacional e ferramenta de mouse customizado). Explorou ferramentas do rodapé como imagens e outros elementos. Utilizou, durante todo o experimento, os recursos de redimensionamento de fonte do navegador. Sua dificuldade fez com que ele se aproximasse muito da tela do computador. Necessitou de intervenção do pesquisador para utilizar a área de chat e a utilizou com dificuldade, em função dos tamanhos dos elementos. Dentre as considerações feitas pelo pesquisado, ele comenta que a área de chat é inadequada para a utilização por pessoas de deficiência visual; não é possível redimensionar o tamanho das letras e, ao fazer o zoom, a própria ferramenta perde o foco e a imagem do Twiddla. Por fim, este sujeito também relatou que o rótulo dos elementos é de difícil visualização e, que da mesma forma, não é possível fazer zoom.

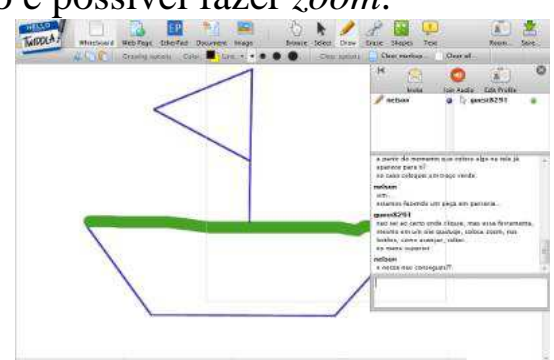

Figura 4. Desenho de João (a partir da tela do pesquisador) 
Durante as interações e com base nos instrumentos utilizados nesta pesquisa, foi possível perceber como os princípios de usabilidade e acessibilidade influenciam na participação ativa do usuário no ambiente do quadro-branco. Os resultados indicam problemas comuns encontrados pelos usuários. Um exemplo disto foi a dificuldade de compreensão e percepção do recurso de chat. Este recurso é fundamental quando falamos em Web 2.0, colaboração e arquitetura de participação.

\section{Considerações}

Neste trabalho, apresentamos algumas considerações sobre como as tecnologias da informática têm propiciado recursos promissores para a comunicação e a participação sociais. Embora haja otimismo com o advento da Web 2.0, as promessas de uma Internet mais democrática ainda parecem passar ao largo das necessidades daqueles que vivem com alguma necessidade especial.

No estudo das propriedades de acessibilidade e usabilidade do software Twiddla, apostamos em uma metodologia que valorizasse as manifestações dos usuários em sua interação conosco e com o software. Com base em nossas experiências, percebemos que alguns recursos possuem uso intuitivo, como as ferramentas de lápis, formas geométricas e cores. No entanto, outros recursos importantes para a autoria coletiva tornam difícil a operação da mesma por pessoas com dificuldades auditivas e visuais. Notamos algumas similaridades nas considerações feitas pelos quatro pesquisados durante as interações. Tais relações foram identificadas pelos cruzamentos dos registros realizados, tanto das observações in loco, quanto dos vídeos, anotações, comentários e o questionário.

Todos os usuários relataram dificuldades que demonstram problemas de acessibilidade e usabilidade, conforme apresentamos no início deste texto. Como exemplo, indicamos o fato de a ferramenta possuir termos em inglês, o que diz respeito à capacidade da interface em se apresentar compreensível ao usuário. Quanto ao aspecto operável, a observação acerca dos problemas deste software recai sobre o uso do chat e como acessá-lo. $\mathrm{O}$ aspecto perceptível pode ser evocado para compreendermos a reclamação dos usuários quando ao tamanho das letras e imagens, que são muito pequenas em sua avaliação. Ainda acerca deste aspecto, os participantes evidenciaram o pouco contraste entre as cores da interface. Por fim, há outros recursos que não possuem relação com o quadro-branco mas que aparecem disponíveis, como é o caso do acesso a outros recursos da ferramenta Twiddla que não fazem parte do quadro-branco e por isso parecem corresponder ao princípio do Feedback, avaliado também negativamente pelos usuários, neste caso. Portanto, nossos resultados, como mostram os relatos, indicam a necessidade de pequenos ajustes no quadro-branco para que se torne mais acessível e permita maior facilidade de uso. Como exemplo, a área de chat não é perceptível (não tem forma clara) e compreensível (não é legível).

No primeiro desafio, os sujeitos tiveram um tempo de ambientação no quadrobranco. Já no desenvolvimento do segundo desafio, os sujeitos vivenciaram a construção colaborativa de um desenho utilizando o chat também como meio de comunicação com o pesquisador. Pode-se perceber que as pessoas com deficiência visual, mesmo no segundo desafio, continuavam enfrentando a dificuldade com o tamanho dos elementos apresentados em tela. Mesmo recorrendo ao zoom, perdiam características importantes da interface para que pudessem realizar a atividade.

É necessário produzir aprimoramentos que levem a uma maior equidade, na participação de sujeitos com diferentes condições sensoriais nos espaços web. Além do acesso para todos, é importante compreender que é preciso que a tecnologia utilizada 
(hardware ou software) seja simples, fácil de usar e configurar e, principalmente, que possa agregar valor à experiência de aprendizagem dos sujeitos que a utilizam. A tecnologia não deve ser o foco e nem a barreira para o acesso. $O$ foco principal deve recair sobre os efeitos produzidos, como frutos, principalmente, da coprodução, da natureza das atividades colaborativas e das competências que emergem da coletividade: trabalho em equipe, responsabilidades e espaço compartilhados, objetivos em comum, troca de ideias e afinidades.

\section{Referências Bibliográficas}

CHISHOLM, W., VANDERHEIDEN, G. JACOBS, I. Web Content Accessibility Guidelines 1.0. W3C Recommendation, 1999. Disponível em <http://www.w3.org/TR/1999/WAI-WEBCONTENT-19990505/> Acesso em: 15 de dez. 2011.

CONFORTO, D., SANTAROSA, L. M. C. Acessibilidade à Web: Internet para Todos. Revista de Informática na Educação: Teoria, Prática - PGIE/UFRGS. v.5, n.2, 2002, p.87-102.

COUTINHO, C. P., JUNIOR, J. B. B. Blog e Wiki: Os Futuros Professores e as Ferramentas da Web 2.0. In MARCELINO, M. J.; SILVA, M. J. (Orgs.) SIIE'2007: actas do Simpósio Internacional de Informática Educativa, n.9, Porto, Portugal, 2007, p.199-204.

DEMOLY, K. R. A. Escrituras na convergência de mídias. Universidade Federal do Rio Grande do Sul, 2008. Tese de doutorado.

DESPRET, V. Naissance d'une théorie éthologique. La danse du cratérope ecaillé. Paris: Les empecheurs de penser em rond, 1996.

DESPRET, V. The body we care for: Figures of anthropo-zoo-genesis. Body and Society, n.10(2-3), p.111-134, 2004.

DESPRET, V. Os dispositivos experimentais. Fractal, Rev. Psicol., Rio de Janeiro, v.23, n.1, 2011. Disponível em: <http://www.scielo.br/scielo.php?script=sci_arttext\&pid=S198402922011000100004\&lng=en\&nrm=iso > Acesso em: 15 de jan. 2012.

JENKINS, H. (2006). Confronting the Challenges of Participatory Culture. Chicago, IL, MacArthur Foundation.

LATOUR, B. Como falar do corpo? A dimensão normativa dos estudos sobre a ciência. In J. A. Nunes \& R. Roque (Orgs.) Objetos impuros. Experiências em estudos sociais da ciência. Porto: Edições Afrontamento, 2007, p.39-61.

MATTAR, J. Games em educação: como os nativos digitais aprendem. São Paulo: Pearson Prentice Hall, 2010.

NIELSEN, J. Usability Engineering. Academic Press, 1993.

OLIVEIRA, R. A. S. Acessibilidade na Web 2.0: criação de uma interface de apoio à leitura de tag clouds por utilizadores com deficiência visual. Universidade de Aveiro, Portugal. Dissertação de Mestrado, 2009.

O'REILLY, T. O que é web 2.0 - Padrões de design e modelos de negócios para a nova geração de software, 2005. Disponível em: <http://pressdelete.files.wordpress.com/2006/12/o-que-e-web-20.pdf> Acesso em: 10 de dez. 2011.

PRIMO, A. O aspecto relacional das interações na Web 2.0. In: Revista da Associação Nacional dos Programas de Pós-Graduação em Comunicação, 2007, p.2-21. Disponível em: <http://www6.ufrgs.br/limc/PDFs/web2.pdf> Acesso em: 11 de maio 2012. 